\title{
The primacy of the mental in the explanation of human action
}

\author{
Andrei A. Buckareff \\ Marist College \\ Jing Zhu \\ Sun Yat-Sen University
}

\begin{abstract}
The mentalistic orthodoxy about reason-explanations of action in the philosophy of mind has recently come under renewed attack. Julia Tanney is among those who have critiqued mentalism. The alternative account of the folk practice of giving reason-explanations of actions she has provided affords features of an agent's external environment a privileged role in explaining the intentional behaviour of agents. The authors defend the mentalistic orthodoxy from Tanney's criticisms, arguing that Tanney fails to provide a philosophically satisfying or psychologically realistic account of reason-explanation of action.
\end{abstract}

\section{Keywords}

Reason-explanations, folk psychology, action theory, philosophy of mind, philosophy of psychology.

\section{Introduction}

In response to the question, 'What distinguishes actions which are intentional from those which are not?,' G.E.M. Anscombe answered as follows. 'The answer [is] ... that they are the actions to which a certain sense of the question 'Why?' is given application; the sense is of course that in which the answer, if positive, gives a reason for acting' (1957/2000: 9). The prevailing orthodoxy in the philosophy of mind and action has taken the reason(s) for acting to be mentalistic. Accord-

Disputatio, Vol. III, No. 26, May 2009

Received on 25 February 2009 
ing to the mentalistic orthodoxy, ${ }^{1}$ an action is explained and justified by some practical reasons an agent has where the reasons are expressed by the propositional contents of some mental states that are introspectively available and either identical to or realized by some neural states of the agent qua organism, typically some combinations of relevant cognitive and conative states. ${ }^{2}$ So mentalism can be summarized as the thesis that (1) reasons for action are psychological states of agents and (2) such states are necessary components of reason explanations of action. Any theory that endorses (2) while rejecting (1) is not a version of mentalism. ${ }^{3}$ By 'mentalism' and 'mentalistic orthodoxy' we mean the thesis that (1) and (2) are both true.

Recently, the mentalistic orthodoxy regarding folk psychological explanations of action has come under attack. Opponents of mentalism argue that reasons for action and explanations in terms of them are not necessarily mentalistic. According to these philosophers, who Alfred Mele refers to as 'objective favourers theorists', the reasons that explain and justify an action are not always the internal mental states of an agent. Rather, they are often 'items that objectively favour courses of action' (Mele 2007: 91).

\footnotetext{
${ }^{1}$ Leading recent defences of this view can be found in Davidson 1963, Dretske 1988, Ginet 1990, McCann 1998, Mele 1992 and 2003, Roth 1999, Schueler 2003, and Sehon 2005. These authors differ from one another with respect to the details of their accounts of reasons explanations, but all of their accounts share in common a commitment to the central features of what we are calling the 'mentalistic orthodoxy'.

${ }^{2}$ This claim about the mental states that explain action is consistent with either internalism or externalism about mental content. While the content of an agent's mental state that explains her action is relevant, whether content is wide or narrow makes no palpable difference for whether or not the mentalistic orthodoxy is correct. For in either case, we still infer that an agent has the relevant state with the relevant content and that the state with that content explains, or is a proper part of the complete explanation of why an agent acts as she does. For similar reasons, contra Tanney, we regard the debate between causalists and non-causalists about reasons explanations to be a distraction when considering the debate between mentalists and anti-mentalists.

${ }^{3}$ Scanlon 1998 and Dancy 2000 are both examples of accounts of acting for reasons and reason-explanations that accept (2) and reject (1). They are, thus, not versions of what we mean by 'mentalism'.
} 
There are some important differences among those who reject mentalism. So 'anti-mentalism' is best regarded as a purely negative thesis that rejects the following thesis as false:

An explanation $E$ of an action $A$ of an agent $S, E$ is a reason explanation of $A$ only if some hidden, inner mental states of $S$ 's constitute $S$ 's reasons for action and are included in $E$.

Consider the following examples of anti-mentalism in the recent literature. Rudiger Bittner claims that, 'we understand our actions primarily in terms of their place among things happening, not in terms of our attitudes with regard to things happening' (Bittner 2001: 110). Jonathan Dancy makes similar claims, asserting that 'Even the most cursory glance at the sorts of reason we actually give, in explaining our own actions or those of others, reveals that while some certainly seem to be characterized in terms of a psychological state of the agent, others equally certainly do not' (2000: 15). ${ }^{4}$ T.M. Scanlon endorses a view similar to Dancy's. He writes that, 'A reason is a consideration that counts in favour of some judgment-sensitive attitude, and the content of that attitude must provide some guidance in identifying the kinds of considerations that could count in favour of it' (1998: 67). Finally, most recently, Julia Tanney has added her voice to the growing chorus of dissent from mentalism. ${ }^{6}$

In this paper, we will focus on Tanney's case against mentalism. Tanney ascribes features of an agent's external environment a privileged role in providing reason-explanations of actions. By 'looking closely at the kinds of considerations we actually use to reach agreement in our ordinary (non-philosophical and non-theoretical) judgments about a person's reasons for acting', she aims at showing that 'we are not obliged to accept the philosophical thesis that someone's acting for reasons depends on the existence or occurrence of something hidden or inner which is a candidate spring-board for her action'

${ }^{4}$ For a recent critique of Dancy, see Mele 2007; see also Mele 2003, chapter 3.

${ }^{5}$ For a recent critique of Scanlon, see Mele 2003: 76-79.

${ }^{6}$ It is worth noting that the emphasis in the work of Dancy and Scanlon is on the justificatory role of reasons. Tanney's focus is on the explanatory role of reasons in folk psychology. For a mentalistic treatment of both that takes seriously the role of external considerations in justifying action but affords reason states a privileged role in explaining and justifying action, see Mele 2003. 
(2005: 339-40). Regarding such states, she explains that they would be hidden if only available upon introspection. 'They would also be so hidden if we were referring either directly or indirectly to physical states of the organism' (2005: 340). If Tanney is correct about the dispensability of such states for the purposes of providing reason explanations, the implications would prove dramatic for how many philosophers of mind and action think about folk psychological explanations of action.

Referring to the hidden and inner mental states posited by most philosophers of mind is unnecessary much of the time, according to Tanney. For instance, being asked why a woman runs out of a building that is on fire, Tanney claims that learning the circumstances in which the action takes place is satisfactory for a reason explanation. Tanney then comments as follows.

In being satisfied with learning about the circumstances we do not necessarily want or need to know anything more - anything more particular, say, about the agent's point of view or state of mind. This raises the following question. In asking for explanations of actions, and in being satisfied when we learn more about the circumstances in which the action occurred, have we not learned the reason for action? (Tanney 2005: 338)

Our answer to Tanney is that it is not obvious that we have learned the reason for action when we learn facts about an agent's environment. We may have learned something about the causal history of why an agent acted. But we are reluctant to agree that we have learned the agent's reason for acting. What we learn by merely citing external factors alone is not adequate for a reason-explanation of the agent's action.

In what follows, we will defend the mentalistic orthodoxy as characterized above. In doing so, we will argue that Tanney fails to provide a philosophically satisfying or psychologically realistic account of the practice of providing reason-explanations of action. Our case against Tanney will be made by challenging each of the three theses she develops (2005: 340).

1. We do not need to appeal to inner states of an agent in explaining her action; rather, all we need to resolve any explanatory difficulties is 'a wider view of the context or circumstances in which the action takes place'. 
2. When we do need to enquire about the agent's conception of the circumstances that explain her action, in normal cases this does not 'lead us to look for hidden, inner events that may be the causes of her action'.

3. Cases where we do consider an agent's inner mental states and events in explaining her action 'do not lend support to the idea that reasons are hidden or inner causes of action, nor do these cases provide the model for how reason-explanation in general should be understood. On the contrary: there are good reasons to see these cases as special and as dependent on the other ones'.

All three theses are untenable. They are presented as 'merely' philosophical claims and not empirical claims. However, each thesis implies or explicitly makes claims about our actual practices as interpreters and explainers of the actions of ourselves and others. The theoretical claims made by Tanney do not stand up under scrutiny. Moreover, recent experimental literature that describes our folk psychological practices does not support any empirical claims Tanney makes under a merely theoretical guise.

There is much at stake in this debate. A widely accepted understanding of folk psychological explanations in the philosophy of mind is mistaken if Tanney is right. Additionally, there are deep metaphilosophical issues nearby. Specifically, there is the matter of the kinds of claims we can justifiably make about folk theories from the comfort of our arm-chairs without having to either consult the extant empirical research on the topic under consideration or getting out and doing the research ourselves. ${ }^{8}$

${ }^{7}$ The experimental literature we have in mind is the recent work in attribution theory by Bertram F. Malle and his colleagues in defence of what Malle has christened the 'folk-conceptual theory of explanation'. See Malle 1999, 2001, and 2004. See also Malle, Knobe, O’Laughlin, Pearce, and Nelson 2000.

${ }^{8}$ Witness the growth of the experimental philosophy movement that involves philosophers in deploying the methods of social psychology in the service of examining the status of folk intuitions about philosophical doctrines, among other things. For recent discussion about the methods, value, and philosophical significance of experimental philosophy, as well as various approaches to the goals of experimental philosophy, see Kauppinen 2007, Knobe 2007, and Nadelhoffer and Nahmias 2007. 


\section{Thesis One}

We agree that it is not always necessary to appeal to the inner, hidden states of an agent to provide an explanation of her actions. One can provide an explanation in terms of environmental factors that help explain an agent's 'inner' reasons for acting. ${ }^{9}$ But we can hardly be said to understand the reason why an agent acted as she did on such a basis alone. An adequate explanation of why an agent acted as she did requires that we know both about the history of what motivated her action and what is directly responsible for her acting as she does. This cannot be done without at some point invoking an agent's reasons for acting, understood as mental states that are hidden from others but whose existence is inferred in third-personal folk explanations of action. This is why our common-sense explanations of actions typically do refer to the internal mental states of agents, either explicitly or implicitly.

Tanney provides a variety of permutations of her fire example throughout her essay, some of the more detailed versions of which are alleged to resolve our third-person difficulties in explaining action without offering mentalistic explanations. Contra Tanney, we think that in most cases we need to appeal to the inner states of an agent in order to explain why an agent acted. In cases where external conditions provide some explanation of an agent's behaviour, a more robust explanation why an agent acted can only be given by referring to the agent's relevant mental states that motivated her to act.

Suppose that you hear a fire alarm. When asked why it is ringing, you respond by saying that 'The building is on fire'. You have clearly explained the behavior of the fire alarm. Admittedly, there is more

\footnotetext{
${ }^{9}$ Alfred Mele notes that such external factors constitute normative reasons for action, but they are not the same thing as the reasons that motivate and directly explain why an agent acted. He writes that, where 'reasons* for action' are defined as belief-desire complexes and intrinsic desires to perform some action, 'intentional actions are to be relatively directly explained at least partially in terms of motivation-encompassing reasons* for action, and when normative reasons (all of which are strictly external facts) contribute to explanations of intentional actions, they do less directly, by way of making a causal contribution to the acquisition of motivation-encompassing reasons* or by way of a causal contribution made by an agent's apprehending a normative reason' (Mele 2003: 84). Mele's account is consistent with what we say later about what Bertram Malle calls "causal history of reasonexplanations' (2000: 276-78).
} 
you can say about the mechanisms of the fire alarm that detect smoke and how the alarm rings as an effect of detecting smoke. But we suspect most would be satisfied with the explanation in terms of the environmental causes of the alarm ringing. Our guess is that folk practice would not typically involve referring to the inner workings of the fire alarm to explain its behaviour. Now suppose you respond by saying 'The building is on fire' when asked why Jane flees the building. Structurally, the two explanations are similar given that they both explain behaviour by referring to the circumstances. But it is not obvious in the case of Jane that we do not need to look for an inner mentalistic explanation nor that the folk do not offer such explanations. Neither is it obvious that the environmental explanation does not disguise a mentalistic explanation that is presumed to be necessary by explainers of action.

When explaining the intentional behaviour of humans we assume that they are agents who are capable of being responsive to reasons. The capacity of being responsive to reasons is very general and domain-crossing, rather than domain- or task-specific, as in the case of the fire alarm. ${ }^{10}$ And the reasons to which they respond are not merely external environmental factors, but how the world is represented in the conscious contents of beliefs and pro-attitudes in deliberation and decision-making.

The difference between an explanation in terms of the reasons we ascribe to agents with the capacity for reasons-responsiveness and explanations merely in terms of environmental factors can be illus-

${ }^{10}$ In Discourse on the Method (Part V), Descartes says:

even though such machines might do some things as well as we do them, or perhaps even better, they would inevitably fail in others, which would reveal that they were acting not through understanding but only from the disposition of their organs. For whereas reason is a universal instrument which can be used in all kinds of situations, these organs need some particular disposition for each particular action; hence it is for all practical purposes impossible for a machine to have enough different organs to make it act in all the contingencies of life in the way in which our reason makes us act (1637/1985: 140).

Though it has become an open question whether modern computing machines can exhibit diverse behaviours appropriate to their environments and therefore be judged as acting for reasons, Descartes' thesis that 'reason is a universal instrument which can be used in all kinds of situations,' as it seems to us, still obtains. 
trated by considering the following three responses to the question 'Why did Jane flee the building?'11

(1) 'Because she thought the building was on fire'.

(2) 'Because the building was on fire'.

(3) 'Because she fears dying in a fire'.

Now compare (1)-(3) to the following three responses to the question 'Why did Jane go to the pub?'

(4) 'Because she wanted a pint of ale'.

(5) 'Because the pub serves ale'.

(6) 'Because she is a drunk'.

Responses (1) and (4) are clearly mentalistic explanations that explainers of action will employ. In fact, notice that (1) is a natural explanation that an observer may offer (especially if the building is not actually on fire). (4) is an explanation the actor may offer (only in the first-person) when asked why she is going to the pub. It would be odd for the one acting to say that she is going to the pub either because it serves ale (response 5) or because she is a drunk (response 6). ${ }^{12}$ However, an observer may naturally offer an explanation in terms of the environment or in terms of a character trait of the agent who is acting (similarly, an agent may be prone to explain her acting by referring to the environment or her relevant character trait-viz., being afraid of dying in a fire). But none of this means that we do not have to or that we do not in fact take into account the 'hidden, inner' mentalistic explanations of behaviour such as we get with (1) and (4).

What Tanney fails to recognize, but the empirical evidence suggests, is that most cases of explaining action either involve an explicit reference to an inner mental state or they imply the presence of such a state. The value of learning more about an agent's context or circumstances in acting provides us with more evidence for the inner, 'hidden', mental states that motivate and explain the agent's

\footnotetext{
${ }^{11}$ See Knobe and Malle, 2002.

${ }^{12}$ However, as Bertram Malle pointed out to us, (5) may be a perfectly natural explanation for an agent to offer in the first-person to explain his behaviour. This may be the case if mentioning this fact is selectively important, e.g., 'It's the only pub that serves ale'.
} 
action even in the absence of mental state markers being used in the explanation of behaviour. Tanney's claim that learning more about the context and circumstances of an agent in acting as somehow counting against the need for a mentalistic explanation betrays her failure to recognize that, as Bertram Malle, et. al., have noted in their work on attribution theory, 'folk explanations of behaviour can refer to the agent's motivation or beliefs even though the words in which they are expressed mention only the situation' (2000: 310). For instance, someone may ask why Juan bought a house in the country, to which you or Juan may reply 'Because it is secluded' (Malle, et. al. 2000: 319). The 'linguistic surface' of such an explanation mentions the circumstances and context of Juan's action. Such explanations refer to reasons 'that have no mental state marker but whose reason content refers to the situation' (Malle, et. al., 2000: 318). Juan believes the house is in a secluded location, and we can infer that living in a secluded location is something he desires. Moreover, it would be reasonable to expect Juan to express that the house satisfies a desire of his absent any mental state markers. Similarly, we may agree with Tanney that the agent in her example flees the building because it is on fire. However, saying 'Because it is on fire' in response to the question why an agent flees a building would express the content of a belief that lacks any explicit mental state markers that figures in a mentalistic reasonexplanation of the agent's action. From the observer's perspective, the more we learn about an agent's context and circumstances, the more we learn about the mental states and events that motivate and explain the agent's action. Merely learning about the environment without making any inferences about the inner mental states of the agent in our explanations would be strange indeed, especially since the mental states can help fill out an otherwise skeletal putative reason-explanation of an action in terms of circumstances.

Tanney's reason-explanations look more like what Malle calls 'causal history of reason explanations' (2000: 276-78). ${ }^{13}$ In the case of Jane, (3), (5), and (6) would be examples of such explanations. ${ }^{14}$ Such

${ }^{13}$ See also Malle 1999: 32-33; and Malle, et al. 2000: 310-313.

${ }^{14}$ In an earlier version of this paper we included (2) among the list of causal history of reason explanations. However, Bertram Malle correctly pointed out to us that (2) is a belief reason with the mental state marker omitted. 
explanations 'describe the context, background, or origin of reasons' and are not characterized by the features typically taken as indicative of reasons that figure in folk explanations of intentional action (discussed in the next section) (Malle 2000: 276). Such explanations account for about $20 \%$ of the explanations of intentional behavior in studies ${ }^{15}$ In the remainder of the cases, the folk practice is to cite the inner mental states of agents (Malle 2000: 275).

Some may insist that we can distinguish the reasons that explain why an agent acts as she does from the mental states that directly motivate her action. The reasons that explain action are external to the agent. And at least a proper part of the motivation an agent has for acting is internal to her. We have already conceded at the beginning of this section that such external facts are part of an explanation of action. They constitute part of an agent's overall reasons for action that explain why she acts as she does. But, as Malle notes, their explanatory role is historical. As such, these facts play a significant role. But there is more to a complete explanation. We need an account of the proximate explanation of an agent's action. This requires that we invoke 'inner' mental states. And to the extent that we are after an account of what the folk practice is, the evidence indicates that the folk practice involves citing the inner mental states of an agent in explaining why an agent acted as she did.

We conclude this section with a metaphilosophical observation about the limits of armchair philosophy. Tanney and those sympathetic to her approach fail to recognize that it is methodologically inadequate to generalize from a single or a few examples to account for the folk practice of offering reason-explanations of action. She selectively employs examples that focus on the linguistic surface of explanations and offers no empirical data to support her claims about what the actual folk practice is. At best, we know what Tanney's intuitions are about reason-explanations. But, unlike Malle, she tells us nothing about what the folk theory is. An examination into folk attitudes about reasons explanations must be systematic and empirical. This cannot be accomplished from the comfort of an armchair.

${ }^{15}$ Malle 1999: 34) writes, regarding the frequency and the conditions under which subjects offer causal history of reason explanations, that 'With respect to frequency, research in our lab has found a prevalence of 6-32\% across numerous data sets...' 


\section{Thesis two}

Tanney may respond to the foregoing by agreeing that we sometimes must make use of mentalistic concepts, but this does not mean that we hypothesize 'inner, hidden causes' of action.

Our use of mental concepts in explaining the actions of an individual answers to the same requirement as citing facts about the circumstances in searching for her reasons. That is, we not only cite facts about the circumstances but also attribute intentions, beliefs, and other propositional attitudes to an individual because doing so helps explain her actions. In talking here about what the agent realized or failed to realize, or knew or did not know, then, we have not yet moved away from the practice of reason-explanation. Talk about what she knew or realized is simply in this case a reconstruction of how it makes sense for her to have acted in the circumstances. We do not have, in particular, a more detailed understanding of her mind that is not derived from our quest to understand her reasons for acting. (Tanney 2005: 343)

Notice that we are merely citing facts about the circumstances in which an agent acts when we invoke intentional concepts in our explanations of action according to Tanney. What we are not doing is hypothesizing inner hidden causes that are the agent's reasons for acting (Tanney 2005: 343). But is this right? There are at least two reasons why Tanney is wrong.

First, notice that thesis two, and the arguments Tanney offers in its support, involves, at least implicitly, an empirical claim about our practices of providing common-sense explanations of action. What is clear is that this is not a mere conceptual claim. It is a claim about our practices as explainers of purposeful behaviour. But this claim does not stand up under scrutiny.

Recent empirical evidence suggests that folk explainers of action assume two features of reason explanations: (1) what counts as an explanation of action must refer to an agent's own subjective reasons for which she formed an intention to act (Malle 2001: 268), and (2) there is a 'rational link between the reasons and the intended action' 
(Malle 2001: 270). ${ }^{16}$ The first of the two features is the most important for our own purposes in critiquing Tanney.

As we noted in the previous section, what Tanney describes with the fire example is the causal history of a reason explanation. She is urging that we treat inner mental states and events of agents in the same manner. She writes, regarding her use of mental states to explain why the agent in her example flees the burning building, that

our use of intentional concepts, like our description of the wider circumstances, was motivated by what would enable us to see her action as reasonable. But not once, in reconstructing how these explanations are offered, rejected, and accepted, have we attempted, or felt the need, to probe into some inner or hidden state of the agent. The use we made of mental concepts to interpret her seemed a way of allowing us to understand the agent's actions in the circumstances. (2005: 346).

Tanney is suggesting that making use of intentional concepts supplements explanations in terms of external factors. But is this right? Malle notes that about $80 \%$ of the time subjects offer reasonexplanations that are mentalistic, making full use of intentional concepts (2001: 275). If the empirical studies on folk explanations of action are right, then Tanney has things backwards. We typically prefer mentalistic explanations of action and only consider context and circumstance as a heuristic to help us understand and 'get to' the elusive 'inner' reasons of agents.

The second problem for Tanney regarding her second thesis is related to our earlier point about human agents being reasons responsive. Tanney ignores the fact that an agent's conception of the circumstances in which she acts can only inform her of what is happening in her environment. Different people in the same environment may share the same experience, but they can and often do act differently. In fact, the same agent may have the same conception of the circumstances at different times, but she may act quite differently in the different situations. For instance, Juan may find himself in a steakhouse at two different times. He may have had no problem with eating meat at $t_{1}$ whereas

${ }^{16}$ When agents have the goal of managing impressions others form of them (specifically, when trying to appear rational), agents offer more explanations in terms of their beliefs (whether marked or unmarked) than in terms of their conative states. See Malle, et al. (2000: 320-322 (Study 5)) for the details of an experiment and the data. 
at $t_{2}$, after becoming a vegetarian, he does. An explanation of Juan's eating meat on one occasion and abstaining on another requires knowing more about Juan than that he is in a steakhouse or that he even has the trait of being a meat-eater or a vegetarian. We explain Juan's acting in different ways by referring to his beliefs and wants on the separate occasions to which he is responsive as a rational agent. Such a situation is not unique or rare. We normally need to know about the inner mental states and events to explain differences between agents and within an agent at different times.

\subsection{Thesis three}

Thesis three, like thesis two, includes an empirical claim about our folk practice of explaining actions. Tanney's claim to the effect that mentalistic explanations are 'special' and 'dependent' on non-mentalistic explanations is dubious. We believe that our foregoing remarks in response to theses one and two should suffice to address this particular claim. It seems that our normal practice of explaining actions does involve hypothesizing the existence of inner mental states and events. And we believe we have offered good reasons for accepting this understanding of what we do when we offer reason-explanations. In fact, contrary to Tanney, when we supply reason-explanations of action by merely citing facts about the circumstances in which an agent acts, it seems we take it for granted that these cases are either special or dependent on mentalistic explanations. The evidence we cited from recent work in attribution theory in the past two sections supports this intuition. So, in the case of Jane running from the house on fire, she runs from it because she believes it is on fire and wants to live (or wants not to die). Environmental explanations are parasitic upon such mentalistic explanations and are explanatorily relevant only if they either refer to the contents of an agent's mental states or are relevant causal history factors that gave rise to the agent's reasons for acting (even if the reasons are not known in full detail). ${ }^{17}$

Finally, contra Tanney, defenders of mentalism are not claiming that it is in general the case that 'a process of deliberation, reflection, introspection, story-telling or narrative occurs before a fully-fledged,

\footnotetext{
${ }^{17}$ Thanks to Bertram Malle for his help with articulating and accounting for the role of environmental explanations.
} 
language-speaking rational agent acts' (2005, p. 350). We are claiming that the purposive behaviour of agents is preceded by inner mental states and events (that are hidden from others, but inferable on the basis of the overt bodily actions and verbal reports of agents) that provide the reasons for which agents act and explain their actions. It is only by hypothesizing the existence of such states and events, and considering the evidence for their existence that we can hope to provide anything like an accurate explanation of why any agent acts as she does. The context and circumstance of an action may defeat or support what we infer about the inner mental states of agents whose intentional behavior we try to explain. But a complete explanatory account of an agent's action in terms of her reasons requires that we hypothesize the existence of reasons the agent would recognize as reasons for which she acted, reasons that not only explain, but justify her acting as she did — such reasons are mentalistic.

\section{Conclusion}

We have shown that the mentalistic orthodoxy is safe from Tanney's criticisms. Our actual practices favour the traditional mentalistic account of reason-explanations taken for granted by the majority of philosophers. Tanney's criticisms of mentalism are challenging; but they ultimately fail. ${ }^{18}$

Andrei A. Buckareff Department of Philosophy and Religious Studies Marist College Poughkeepsie, NY 12601, U.S.A. andrei.buckareff@marist.edu

Jing Zhu Institute of Logic and Cognition Sun Yat-Sen University Guangzhou 510257, China zhujing6@mail.sysu.edu.cn

\footnotetext{
${ }^{18}$ Thanks to Bertram Malle and two referees for this journal for helpful comments on earlier versions of this paper.
} 


\section{References}

Anscombe, G.E.M. 1957/2000. Intention. Cambridge, MA: Harvard University Press.

Bittner, Rudolf. 2001. Doing Things for Reasons. New York: Oxford University Press.

Descartes, René. 1637/1985. Discourse on the Method, in The Philosophical Writings of Descartes 1637, translated by J. Cottingham, R. Stoothoff and D. Murdoch. Cambridge: Cambridge University Press.

Dancy, Jonathan. 2000. Practical Reality. New York: Oxford University Press.

Davidson, Donald. 1963. Actions, Reasons, and Causes. Journal of Philosophy 60: 685-700.

Dretske, Fred. 1988. Explaining Behavior: Reasons in a World of Causes. Cambridge, MA: MIT Press.

Ginet, Carl. 1990. On Action. New York: Cambridge University Press.

Kauppinen, Annti. 2007. The Rise and Fall of Experimental Philosophy. Philosophical Explorations 10: 95-118.

Knobe, Joshua. 2007. Experimental Philosophy and Philosophical Significance. Philosophical Explorations 10: 119-21.

Knobe, Joshua. and Malle, Bertram. 2002. Self and Other in the Explanation of Behavior: 30 years later. Psychologica Belgica 42: 113-30

Malle, Bertram. 1999. How People Explain Behavior: A New Theoretical Framework', Personality and Social Psychology Review 3: 23-48.

Malle, Bertram. 2001. Folk Explanations of Intentional Action. In Intentions and Intentionality: Foundations of Social Cognition, edited by B. Malle, L. Moses, and D. Baldwin. Cambridge, MA: MIT Press.

Malle, Bertram. 2004. How the Mind Explains Behavior: Folk Explanations, Meaning, and Social Interaction. Cambridge, MA: MIT Press.

Malle, Bertram, Knobe, Joshua, O’Laughlin, Matthew, Pearce, Gale, and Nelson, Sarah. 2000. Conceptual Structure and Social Functions of Behavior Explanations: Beyond Person-Situation Attributions. Journal of Personality and Social Psychology 79: 309-326.

McCann, Hugh. 1998. The Works of Agency. Ithaca: Cornell University Press.

Mele, Alfred. 1992. Springs of Action: Understanding Intentional Behavior. New York: Oxford University Press.

Mele, Alfred. 2003. Motivation and Agency. New York: Oxford University Press.

Mele, Alfred. 2007. Reasonology and False Beliefs. Philosophical Papers 36: 91-118.

Nadelhoffer, Thomas and Nahmias, Eddy. 2007. The Past and Future of Experimental Philosophy. Philosophical Explorations 10: 123-49.

Roth, Abraham. 1999. Reasons Explanations of Actions: Causal, Singular, and Situational. Philosophy and Phenomenological Review 59: 839-74. 
Scanlon, T.M. 1998. What We Owe to Each Other. Cambridge, MA: Harvard University Press.

Schueler, G.F. 2003. Reasons and Purposes: Human Rationality and the Teleological Explanation of Action. New York: Oxford University Press.

Sehon, Scott. 2005. Teleological Realism: Mind, Agency, and Explanation. Cambridge: MIT Press.

Tanney, Julia. 2005. Reason-Explanation and the Contents of the Mind. Ratio 18: 338-351. 